\title{
Dentre tantos caminhos, uma escolha: das Tecnologias da Informática na escola às Performances Matemáticas Digitais - Trajetória por programas governamentais brasileiros e projetos de pesquisa
}

\author{
Among so many ways, a choice: from Computer Technologies in school to Digital Mathematical \\ Performances - Trajectory by brazilian governmental programs and research projects \\ Entre muchas formas, una elección: desde Tecnologías de Computadoras en la escuela a \\ Actuaciones Matemáticas Digitales - Trayectoria de programas gubernamentales y proyectos de \\ investigación
}

Eduardo dos Santos de Oliveira Braga

ORCID: https://orcid.org/0000-0002-8742-6981 Instituto Federal de Educação, Ciência e Tecnologia do Rio de Janeiro, Brasil E-mail: eduardo.braga@ifrj.edu.br

Vinícius Munhoz Fraga

ORCID: https://orcid.org/0000-0003-1297-5051 Instituto Federal de Educação, Ciência e Tecnologia do Rio de Janeiro, Brasil E-mail: vinicius.fraga@ifrj.edu.br

Marcus Vinicius Pereira ORCID: https://orcid.org/0000-0002-8203-7805 Instituto Federal de Educação, Ciência e Tecnologia do Rio de Janeiro, Brasil E-mail: marcus.pereira@ifrj.edu.br

Giselle Rôças

ORCID: https://orcid.org/0000-0002-1669-7725 Instituto Federal de Educação, Ciência e Tecnologia do Rio de Janeiro, Brasil E-mail: giselle.rocas@ifrj.edu.br

\begin{abstract}
Resumo
As Performances Matemáticas Digitais (PMDs) podem ser compreendidas inicialmente como uma perspectiva da Educação Matemática que integra as artes performáticas e tecnologias digitais à Educação Matemática. Levando em consideração as temáticas que envolvem as PMDs - artes e tecnologias digitais - e tendo como inspiração as produções acadêmicas sobre o assunto, o presente artigo tem por objetivo apresentar, a partir de uma das temáticas das PMDs: tecnologias digitais - uma trajetória que se inicia com a entrada da tecnologia informática nas escolas brasileiras até os mais atuais projetos que envolvem discussões das tecnologias digitais com artes e Educação Matemática, por meio das PMDs. Pautados numa metodologia de pesquisa qualitativa, com o estudo particular do evento Encontro Brasileiro de Estudantes de Pós-Graduação em Educação Matemática para descortinar os atuais projetos de pesquisa sobre tecnologias digitais, dividimos esse artigo em duas seções, a saber: a primeira delas se destina a tratar sobre algumas ações governamentais de incentivo às tecnologias digitais nas escolas públicas brasileiras e a segunda descreve a que ponto chegamos em termos de projetos de pesquisa sobre tecnologias digitais na Educação Matemática, enfatizando, para isso, os projetos ligados às PMDs. Conclui-se, dentre outros fatores, que as PMDs se apresentam como uma potente proposta para o ensino e aprendizagem em matemática uma vez que além de articular as tecnologias digitais à Educação Matemática, preocupa-se em incorporar as artes (performáticas) nesse processo, bem como desmistificar estereótipos da matemática e de quem a pratica, dando protagonismo discente em produções oriundas dos diferentes projetos de pesquisa.

Palavras-chave: Tecnologias digitais; Performances matemáticas digitais; Programas governamentais; Projetos de pesquisa; EBRAPEM; Ensino.
\end{abstract}

\begin{abstract}
Digital Mathematical Performances (PMDs) can be understood initially as a perspective of Mathematical Education that integrates the performing arts and digital technologies with Mathematical Education. Taking into account the themes that involve PMDs - digital arts and technologies - and taking inspiration from academic productions on the subject, this article aims to present, based on one of the themes of PMDs: digital technologies - a trajectory that starts with the entry of computer technology in Brazilian schools until the most current projects that involve discussions of digital technologies with arts and Mathematics Education, through the PMDs. Based on a qualitative research
\end{abstract}


methodology, with the particular study of the event Brazilian Meeting of Graduate Students in Mathematics Education to unveil the current research projects on digital technologies, we divided this article into two sections, namely: the first one is intended to address some government actions to encourage digital technologies in Brazilian public schools and the second describes how far we have come in terms of research projects on digital technologies in Mathematics Education, emphasizing, for this, projects linked to LDCs. It is concluded, among other factors, that the LDCs present themselves as a powerful proposal for teaching and learning in mathematics since, in addition to articulating digital technologies to mathematics education, it is concerned with incorporating the (performing) arts in this process, as well as demystifying stereotypes of mathematics and of those who practice it, giving protagonism to students in productions from different research projects.

Keywords: Digital technologies; Digital mathematical performances; Government programs; Research project; EBRAPEM; Teaching.

\section{Resumen}

Las Interpretaciones Matemáticas Digitales (PMD) pueden entenderse inicialmente como una perspectiva de la Educación Matemática que integra las artes escénicas y las tecnologías digitales con la Educación Matemática. Teniendo en cuenta los temas que involucran a los PMD - artes y tecnologías digitales - e inspirándose en las producciones académicas sobre el tema, este artículo tiene como objetivo presentar, a partir de uno de los temas de los PMD: las tecnologías digitales, una trayectoria que comienza con la entrada de la informática. tecnología en las escuelas brasileñas hasta los proyectos más actuales que involucran discusiones de tecnologías digitales con las artes y la educación matemática, a través de los PMD. Con base en una metodología de investigación cualitativa, con el estudio privado del evento Encuentro Brasileño de Estudiantes de Posgrado en Educación Matemática para dar a conocer los proyectos de investigación actuales sobre tecnologías digitales, dividimos este artículo en dos secciones, a saber: la primera está destinada a dirigirse a algunos gobiernos acciones de fomento de las tecnologías digitales en las escuelas públicas brasileñas y el segundo describe lo lejos que hemos llegado en términos de proyectos de investigación sobre tecnologías digitales en Educación Matemática, enfatizando, para ello, los proyectos vinculados a los PMA. Se concluye, entre otros factores, que los PMA se presentan como una propuesta poderosa para la enseñanza y el aprendizaje de las matemáticas ya que, además de articular las tecnologías digitales a la educación matemática, se preocupa por incorporar las artes (escénicas) en este proceso, como así como desmitificar los estereotipos de la matemática y de quienes la practican, dando protagonismo a los estudiantes en producciones de diferentes proyectos de investigación.

Palabras clave: Tecnologías digitales; Actuaciones matemáticas digitales; Programas gubernamentales; Proyecto de investigación; EBRAPEM; Enseãnza.

\section{Início da Caminhada}

O caminho é este / tem pedra, tem sol tem bandido, mocinho / tem você amando tem você sozinho / é só escolher ou vai, ou fica. Fui. Martha Medeiros em Poesia Reunida. Porto Alegre: L\&PM, 1999.

Ao longo da história da matemática, o tema tecnologias digitais ganhou fôlego e tem se apresentado em diferentes congressos brasileiros como eixo temático, em pós graduações como linha de pesquisa e em relatos de experiência de diferentes níveis envolvendo reflexões de seu uso por professores de matemática. Com isso, ao decorrer, especialmente das três últimas décadas, alguns programas governamentais brasileiros e projetos de pesquisa se estabeleceram na tentativa de implementar a informática nas escolas, bem como o letramento digital docente e discente. Com isso, torna-se importante refletirmos sobre tal histórico das tecnologias informáticas e identificarmos, a partir do caminho pregresso sobre o tema, os atuais projetos de pesquisa que envolvem o tema tecnologias digitais na Educação Matemática.

Tendo como inspiração as fases das tecnologias digitais em Educação Matemática propostas por Borba, Silva e Gadanidis (2018), objetivamos, neste artigo, apresentar, por meio do caminho trilhado pelas tecnologias informáticas na escola, um projeto de pesquisa que tem ganhado vulto na Educação Matemática que são as Performances Matemáticas Digitais (PMDs). As PMDs são características da quarta fase das tecnologias digitais que possuem os tablets, computadores, laptops, smartphones e a internet rápida como atores. A seguir, no Quadro 1 apresentamos uma síntese das principais características das 
quatro fases das tecnologias digitais que direcionaram nosso caminhar pelos programas e projetos de pesquisa que envolvem tecnologias neste artigo.

Quadro 1: As quatro fases das Tecnologias Digitais em Educação Matemática.

\begin{tabular}{|c|c|c|c|c|}
\hline & Tecnologias & $\begin{array}{c}\text { Natureza ou base tecnológica } \\
\text { das atividades }\end{array}$ & Perspectivas ou noções teóricas & Terminologia \\
\hline $\begin{array}{c}\text { Primeira } \\
\text { fase (1985) }\end{array}$ & $\begin{array}{c}\text { Computadores, } \\
\text { calculadoras simples e } \\
\text { científicas. }\end{array}$ & $\begin{array}{l}\text { Software LOGO } \\
\text { Programação }\end{array}$ & Construcionismo; micromundo. & $\begin{array}{c}\text { Tecnologias } \\
\text { informáticas (TI). }\end{array}$ \\
\hline $\begin{array}{c}\text { Segunda } \\
\text { fase (início } \\
\text { dos anos } \\
\text { 1990) }\end{array}$ & $\begin{array}{l}\text { Computadores } \\
\text { (popularização), } \\
\text { calculadoras gráficas. }\end{array}$ & $\begin{array}{l}\text { Geometria dinâmica (Cabri } \\
\text { Géometre; Geometricks); } \\
\text { múltiplas representações de } \\
\text { funções (Winplot, Fun, } \\
\text { Mathematica); CAS (Maple); } \\
\text { jogos }\end{array}$ & $\begin{array}{c}\text { Experimentação, visualização e } \\
\text { demonstração; zona de risco; } \\
\text { conectividade; ciclo de aprendizagem } \\
\text { construcionista; seres-humanos-com- } \\
\text { mídias. }\end{array}$ & $\begin{array}{c}\text { TI; software } \\
\text { educacional; } \\
\text { tecnologia } \\
\text { educativa. }\end{array}$ \\
\hline $\begin{array}{c}\text { Terceira } \\
\text { fase (1999) }\end{array}$ & $\begin{array}{c}\text { Computadores, laptops } \\
\text { e internet. }\end{array}$ & $\begin{array}{l}\text { Teleduc; e-mail; chat; fórum; } \\
\text { google }\end{array}$ & $\begin{array}{l}\text { Educação a Distância online; } \\
\text { interação e colaboração online; } \\
\text { comunidades de aprendizagem. }\end{array}$ & $\begin{array}{c}\text { Tecnologias da } \\
\text { informação e } \\
\text { comunicação (TIC). }\end{array}$ \\
\hline $\begin{array}{c}\text { Quarta fase } \\
\text { (2004) }\end{array}$ & $\begin{array}{l}\text { Computadores, } \\
\text { laptops, tablets, } \\
\text { telefones celulares, } \\
\text { internet rápida. }\end{array}$ & $\begin{array}{l}\text { GeoGebra; objetos virtuais de } \\
\text { aprendizagem; Applets; vídeos; } \\
\text { YouTube; WolframAlpha; } \\
\text { Wikipedia; Facebook; ICZ; } \\
\text { Second Life; Moodle }\end{array}$ & $\begin{array}{l}\text { Multimodalidade; telepresença; } \\
\text { interatividade; internet em sala de } \\
\text { aula; produção e compartilhamento } \\
\text { online de vídeos; performance } \\
\text { matemática digital. }\end{array}$ & $\begin{array}{l}\text { Tecnologias Digitais } \\
\text { (TD); tecnologias } \\
\text { móveis e portáteis. }\end{array}$ \\
\hline
\end{tabular}

Fonte: Adaptado de Borba, Silva \& Gadanidis (2018, p. 43).

Como parte integrante da quarta fase das tecnologias digitais, as PMDs inicialmente podem ser compreendidas como a articulação das artes (performáticas) e tecnologias digitais à Educação Matemática. Contudo, Borba, Silva e Gadanidis (2018, p. 111) esclarecem que a "noção de PMD envolve pluralidade semântica e conceitual". Nesse sentido, os autores exemplificam citando que as PMDs podem ser concebidas como linha de pesquisa em potencial consolidação em Educação Matemática, ou mesmo podem ser entendidas como enfoque didático e pedagógico para o ensino e a aprendizagem em matemática, ou ainda, com sentido mais usual, as PMDs podem ser compreendidas como "texto-narrativa digital multimodal, principalmente em formato de vídeo digital" (Borba, Silva \& Gadanidis, 2018, p. 111), embora outros tipos de mídias sejam exploradas nas pesquisas sobre o tema.

Das duas temáticas que envolvem as PMDs na Educação Matemática (artes e tecnologias digitais), poderíamos ter optado, neste artigo, seguir um caminho que as apresentassem por meio das artes. Porém, a partir da revisão de literatura previamente realizada sobre o tema é possível identificar produções acadêmicas em nível de mestrado e doutorado que percorrem esse caminho, como, por exemplo, em Lacerda (2015) e Sachser (2019) que destacaram as artes teatrais no estabelecimento de reflexões a respeito das PMDs; por outro lado, não detectamos trabalhos que trilhassem uma trajetória que as apresentassem por meio das tecnologias digitais (SOUZA et al., 2020). Com isso, optamos por seguir esse caminho, mais 
precisamente, das ações de fomento governamental e projetos de pesquisa que envolvem o tema para, assim, elucidarmos alguns projetos que impulsionaram, consolidaram e possibilitaram a produção da maioria dos trabalhos sobre PMDs.

Não é de hoje que o tema informática e educação é pauta de discussões e reflexões para a Educação Matemática. Em 2001, Borba e Penteado sinalizavam que o assunto era tema de debate recorrente nas últimas duas décadas no Brasil e, há um pouco mais de tempo, em outros lugares do mundo. Dicotomicamente, muitas de suas discussões se alinhavaram no sentido de estabelecer de um lado os que a tem como salvadora dos problemas do ensino e do outro lado os que enxergam a utilização da informática como um perigo para a aprendizagem dos alunos. Esses defendem tal periculosidade no sentido de que as tecnologias tornariam os alunos dependentes das máquinas. Questionamento do tipo: "Como o aluno aprenderá a calcular se utilizar calculadora?" está presente no discurso de muitos professores, desde que os computadores foram inseridos no mundo do trabalho e do lazer no final dos anos 80 e início dos anos 90. Parece carecer, para este grupo de pensadores, a reflexão de que os mesmos alunos podem já estar dependentes de outros tipos de tecnologias, como o lápis e o papel (Borba \& Penteado, 2017). Costumeiramente, associa-se à tecnologia apenas os aparelhos tecnológicos digitais, como o computador e os smartphones, esquecendo-se que o termo tecnologias não é restrito aos equipamentos eletrônicos, mas o "conceito de tecnologias engloba a totalidade de coisas que a engenhosidade do cérebro humano consegue criar em todas as épocas, suas formas de uso, suas aplicações” (Kenski, 2008, p. 22-23), sendo, portanto, o lápis, o papel e a própria linguagem exemplos de tecnologias. Acontece que, conforme cita Kenski (2008), o emprego das tecnologias tem se dado de maneira tão natural nas nossas vidas que muitas vezes nem é perceptível o quanto estamos impregnados delas em nosso cotidiano.

Por outro lado, conforme destacam Borba e Penteado (2017), têm-se os que apontam para o computador como a solução dos problemas educacionais. Argumentam com afirmações de que a introdução da informática na educação seria a panaceia dos diferentes obstáculos inerentes ao ensino e à aprendizagem dos alunos. Como se bastasse apenas introduzir o computador na escola para que todos os empecilhos do ensino e da aprendizagem, em um piscar de olhos, fossem descortinados e resolvidos. Nessa linha de raciocínio, parecem faltar algumas reflexões, como dizer quais seriam todos esses problemas que o computador daria conta e relatar como o computador resolveria todos eles. Nesse sentido, dentre outros fatores, Kenski (2008) aponta para a necessidade de compreensão e incorporação pedagógica para que as tecnologias tragam significativas alterações no processo educativo. Fiorentini e Lorenzato (2006, p. 46) ponderam que:

[...] parece haver uma crença, entre alguns responsáveis pelas políticas educacionais, de que as novas tecnologias da informação e comunicação são uma panaceia para solucionar os males da educação atual. [...] se, de um lado, pode ser considerado relativamente simples equipar as escolas com essas tecnologias, de outro, isso exige profissionais que saibam utilizá-las com eficácia na prática escolar.

Das visões extremas apresentadas anteriormente, há também espaço para diferentes posicionamentos. Dentre eles, coadunamos com a defesa de Borba e Penteado (2017) de que a relação entre as tecnologias digitais e a Educação Matemática deve ser vista como transformação da própria prática educativa. Reconhece-se, nesse sentido, que as tecnologias podem favorecer a criação de espaços mais atraentes e significativos para a construção de conhecimentos. É a partir desse posicionamento que este trabalho é construído. Para além, ainda de acordo com os autores supracitados, as justificativas para a presença da informática na Educação Matemática devem ocorrer de duas formas: alfabetização tecnológica e direito ao acesso. A alfabetização tecnológica no sentido da aprendizagem de leitura dessa nova mídia e não na acepção de um curso de informática. Nesse sentido, “a informática na escola passa a ser parte da resposta a questões ligadas à cidadania” (Borba \& Panteado, 2017, p. 17).

De modo abrangente, discute-se como a noção de cidadania deve estar articulada aos projetos de uma sociedade, sejam eles coletivos ou individuas, e aponta a discussão dos valores pessoais e da sociedade como um todo sendo um dos 
deveres da educação para a cidadania. A partir desse olhar, de que a educação deve promover a crítica em relação aos próprios valores que a envolvem, que Borba e Penteado (2017, p 17) acreditam que a discussão sobre a informática na Educação Matemática deve ser compreendida. Logo, “o acesso à informática deve ser visto como um direito e, portanto, nas escolas públicas e particulares o estudante deve poder usufruir de uma educação que no momento atual inclua, no mínimo, uma 'alfabetização tecnológica"; problemática esta que ficou ainda mais evidente diante das desigualdades severamente externadas com o ensino remoto em tempos de pandemia de COVID-19, em todos anos e em todas as modalidades de ensino.

Isso posto, cabe ressaltar que não é objetivo aqui tratar de toda a história da informática na educação, mas sim apresentar, a partir de alguns relevantes projetos governamentais, a história da informática educacional no Brasil. Consideramos necessário este situar histórico por meio destes importantes eventos para clarificarmos como se deu a introdução das tecnologias digitais no ambiente escolar, traçarmos algumas críticas a eles e descortinarmos, posteriormente, alguns dos mais recentes projetos de pesquisa da área no campo da Educação Matemática. Destarte, esse artigo tem por objetivo apresentar, a partir de uma das temáticas que o assunto PMD envolve - tecnologias digitais - uma breve trajetória que se inicia com a entrada da tecnologia informática nas escolas brasileiras até os mais atuais projetos que envolvem discussões das tecnologias digitais com artes e Educação Matemática, através das PMDs. Para isso, esse artigo está dividido em duas seções, a saber: a primeira delas se destina a tratar sobre algumas ações governamentais de incentivo às tecnologias digitais nas escolas públicas brasileiras e a segunda descreve a que ponto chegamos em termos de projetos de pesquisa sobre tecnologias digitais na Educação Matemática, enfatizando, para isso, os projetos ligados à temática PMDs. Antes, porém, de adentrarmos nas discussões das seções, apresentaremos os caminhos percorridos por nossa pesquisa.

\section{Os caminhos Percorridos da Pesquisa}

O caminho percorrido nesta pesquisa possui abordagem qualitativa, de cunho bibliográfico, com análise de material já elaborado sobre o tema em discussão, como, por exemplo, artigos científicos, dissertações e teses. De acordo com Gil (2008), uma das vantagens desse tipo de pesquisa é permitir ao investigador a cobertura de uma gama de informações para a elaboração da reflexão e análise do tema que se quer pesquisar que, neste artigo, é o caminho por programas governamentais brasileiros envolvendo as tecnologias digitais até a compreensão de alguns projetos de pesquisa atuais sobre tecnologias digitais, culminando, assim, nas PMDs.

Para isso, o recorte temporal da pesquisa teve como inspiração as fases das tecnologias digitais em Educação Matemática (Borba, Silva \& Gadanidis, 2018). Com isso, buscamos identificar os principais programas governamentais brasileiros de incentivo à informática educativa desde a década de 90 (fase 1 das tecnologias digitais em Educação Matemática) até os atuais programas e projetos de pesquisa (atual fase 4 das tecnologias digitais em Educação Matemática).

Para a identificação dos principais programas governamentais de incentivo à tecnologia educativa, perfazendo o histórico das três primeiras fases das tecnologias digitais em Educação Matemática, buscamos leituras e referências em artigos, dissertações e teses que se debruçaram em discussões sobre o tema. Na busca por pesquisas nacionais atuais relativas ao tema que integram a quarta fase das tecnologias digitais em Educação Matemática, encontramos nos anais do Encontro Brasileiro de Estudantes de Pós-Graduação em Educação Matemática (EBRAPEM) a possibilidade de descortinarmos as atuais tendências de pesquisa na área. Isso se deu, pois o EBRAPEM é um importante encontro anual e apresenta uma organização singular, cujo participante envia seu artigo junto com a carta do orientador ao evento. Os trabalhos selecionados são brevemente apresentados pelo estudante de pós-graduação em Educação Matemática para que os outros participantes do encontro e o coordenador da seção possam contribuir, discutir, refletir e propor sugestões, podendo ser considerado uma qualificação aberta (Borba, 2003). Com isso, os trabalhos submetidos são, em geral, frutos de pesquisas que estão sendo realizadas pelos estudantes de pósgraduação, das mais variadas instituições e que veem nesse encontro uma possibilidade de discussão e ampliação dos 
horizontes sobre suas respectivas pesquisas em andamento; daí a escolha do evento para conhecermos as tendências de pesquisas atuais da área. O Quadro 2 abaixo representa o caminho percorrido pela pesquisa.

Quadro 2: Caminhos percorridos da pesquisa.

\begin{tabular}{|c|l|l|}
\hline $\begin{array}{c}\text { Fase das tecnologias } \\
\text { digitais em Educação } \\
\text { Matemática }\end{array}$ & \multicolumn{1}{|c|}{ Objetivo da pesquisa } & \multicolumn{1}{|c|}{ Fontes de pesquisa } \\
\hline $\mathbf{1}^{\circ} \mathbf{2}^{\circ} \mathbf{e} \mathbf{3}^{\circ}$ fases & $\begin{array}{l}\text { Apresentar uma breve trajetória que se inicia com a } \\
\text { entrada da tecnologia informática nas escolas brasileiras, } \\
\text { tendo como principais recursos os laboratórios de } \\
\text { informática, os computadores e notebooks. }\end{array}$ & $\begin{array}{l}\text { Documentos oficiais, artigos, dissertações e teses } \\
\text { sobre os principais programas governamentais } \\
\text { brasileiros relacionados às tecnologias informáticas na } \\
\text { escola. }\end{array}$ \\
\hline $\mathbf{4}^{\circ}$ fase & $\begin{array}{l}\text { Descortinar as principais tendências em Educação } \\
\text { Matemática com relação ao tema tecnologias digitais. A } \\
\text { partir disso, focar nas PMDs como uma dessas tendências } \\
\text { específicas da quarta fase das tecnologias digitais. }\end{array}$ & $\begin{array}{l}\text { Anais publicados no Encontro Brasileiro de Estudantes } \\
\text { de Pós-Graduação em Educação Matemática, por ser } \\
\text { umento cujas publicações são fruto de pesquisas em } \\
\text { andamento ou recém concluída. }\end{array}$ \\
\hline
\end{tabular}

Fonte: Autores (2021).

Foram analisados todos os anais que compõe o grupo de discussão 6 (GD 6) do referido evento, que se destina à pesquisa em Educação Matemática, tecnologias digitais e educação a distância, no período de 2014 a 2019 , respectivamente, do XVIII ao XXIII EBRAPEM. A partir desse mapeamento, foi possível identificar os dois principais pesquisadores do GD 6, bem como as diferentes pesquisas encaminhadas por eles em suas respectivas instituições e com seus respectivos pares e orientandos. Com o mapeamento, foi possível canalizar a discussão para as PMDs neste artigo.

\section{Caminho Trilhado: Ações Governamentais de Incentivo às Tecnologias Digitais nas Escolas Públicas Brasileiras}

A novidade era o máximo

Do paradoxo estendido na areia Alguns a desejar seus beijos de deusa Alguns a desejar seu rabo pra ceia

Ó mundo tão desigual, tudo é tão desigual, ô ô De um lado este carnaval, de outro a fome total, ô ô

Trecho da canção “A novidade” escrita por Gilberto Gil em parceria com Hebert Vianna (1986)

Acompanhamos hoje um desenvolvimento tecnológico que tem propiciado o aparecimento de diversificados equipamentos de comunicação e de difusão e acesso à informação. O ambiente escolar está repleto de inúmeros aparatos que compõem algumas das chamadas tecnologias da informação e comunicação (TIC), como os computadores, os notebooks, os ultrabooks, o acesso à internet, os tablets e os smartphones. Algumas dessas tecnologias foram inseridas no contexto educacional por meio de programas e políticas governamentais, com a promessa de melhoria da qualidade do ensino e da aprendizagem. 
A estruturação de políticas governamentais estimulou e promoveu a realização de pesquisas em informática educacional, seu emprego na educação escolar e a formação de professores para o uso das tecnologias digitais na escola. Segundo Tavares (2002), desde os anos 60, há relatos do uso de computadores na educação, com a primeira experiência educacional na área de física na Universidade Federal do Rio de Janeiro. Com o desenvolvimento dos computadores pessoais no Brasil, por volta de 1980, disciplinas de informática foram criadas e incorporadas pelas escolas particulares da época. Destaca-se que tais disciplinas ensinavam a informática e não se ensinava com informática.

Em nível nacional, um dos primeiros estímulos ao uso da tecnologia informática nas escolas brasileiras ocorreu em agosto de 1981 com a realização do I Seminário Nacional de Informática Educativa. A realização desse evento foi uma das primeiras atitudes da equipe formada por integrantes da Secretaria Especial de Informática (SEI), do Ministério da Educação e Cultura (MEC), do Conselho Nacional de Desenvolvimento Científico e Tecnológico (CNPq) e da Financiadora de Estudo e Projetos (Finep) para discutir a introdução da informática nas escolas. Dentre as recomendações oriundas desse evento, destacam-se duas que até os dias atuais influenciam as políticas públicas da área, a saber: o computador deveria ser um meio de ampliação das funções do professor e não de sua substituição; a informática educacional deveria ser adaptada à realidade brasileira, com a valorização da cultura, dos valores sócio-políticos e da educação nacional (Borba \& Penteado, 2017). Nesta década, a partir do evento citado e de investimentos governamentais de informática na educação, alguns projetos públicos se desenvolveram como o Educon, o Formar e o Proninfe; dando vida, posteriormente, ao Proinfo.

Em 1983, o Educon (Educação e Computador) foi criado pelo MEC e pela SEI, cujo objetivo principal era estabelecer centros pilotos em universidades brasileiras para desenvolver pesquisas interdisciplinares sobre a aplicação da informática no processo de ensino-aprendizagem, bem como a formação de recursos humanos. Estes centros pilotos desenvolveram trabalhos pioneiros sobre a avaliação dos efeitos da inserção do computador no ensino de disciplinas dos níveis fundamental e médio e sobre a formação de recursos humanos na área da informática voltada para a educação. Os centros pilotos desenvolveram trabalhos independentes dos outros, conforme projeto submetido por cada universidade envolvida com o Educon, a saber:

- A Universidade Federal do Rio de Janeiro (UFRJ), com uma proposta voltada ao ensino médio, cujo objetivo era analisar os efeitos da tecnologia sobre a postura do professor, a organização escolar e a aprendizagem. A introdução da disciplina Tecnologia educacional: informática e educação no currículo da graduação e da pós-graduação foi um dos aspectos importantes resultantes dessa proposta;

- A Universidade de Minas Gerais (UFMG), com a proposta de um projeto interdisciplinar, cujos objetivos foram a informatização escolar, o desenvolvimento de softwares educacionais, a capacitação de recursos humanos e o emprego da informática na educação especial. Criou-se, com a proposta, a disciplina de Informática em educação na graduação da referida universidade;

- A Universidade Federal de Pernambuco (UFPE), cujos objetivos foram à análise de softwares educacionais na Linguagem $\operatorname{Logo}^{1}$ na aprendizagem dos estudantes e a formação de recursos humanos na área, culminando em cursos e projetos nas áreas de licenciatura e pedagogia;

- A Universidade Federal do Rio Grande do Sul (UFRGS) foi também outro centro piloto envolvido no projeto Educon. Porém, antes mesmo disso, esta universidade já era um espaço que se dedicava aos estudos da introdução da informática na educação. Uma de suas realizações anteriores ao Educon foi a criação do Laboratório de Estudos

\footnotetext{
${ }^{1}$ LOGO: software educacional que foi inspirado na Teoria de desenvolvimento humano de Jean Piaget. Foi criado com o objetivo de possibilitar que alunos e professores reflitam sobre as noções necessárias colocadas nas situações propostas e testem suas hipóteses na resolução desses problemas (Brito \& Purificação, 2011, p. 80).
} 
Cognitivos (LEC), destinado ao desenvolvimento da informática educacional na linha da psicologia genética e ao trabalho com crianças especiais. Com o Educon, integraram-se ao LEC o Núcleo de Informática na Educação e a Faculdade de Educação, atuando todos na pesquisa sobre a Linguagem Logo, na sua introdução na educação escolar e na formação de professores, numa linha construtivista, e na produção de softwares educacionais;

- A Universidade de Campinas (UNICAMP), que como a UFRGS já se preocupava com a introdução da informática na educação, com a existência do Núcleo de Informática Aplicada à Educação (Nied). Com a escolha da UNICAMP como centro piloto, dedicou-se à formação de recursos humanos, à análise de softwares educacionais e ao desenvolvimento de metodologias de utilização da informática na educação escolarizada (Borba \& Penteado, 2017; Tavares, 2002).

Em todos os projetos é possível notar, nos centros pilotos selecionados para compor o Educon, a preocupação com a formação do professor, seja por meio de sua capacitação, ou então pela análise de sua postura diante da introdução desse "novo ator" no contexto escolar, que é o computador. Desde o início da década de 1980, os setores empresarial, industrial e educacional foram marcados pela introdução da informática em suas estruturações. Em 1981, representantes do MEC, da SEI e do CNPq criaram um grupo de trabalho com o objetivo de elaborar o documento Subsídios para implantação do programa de informática na educação. Uma de suas orientações era a particular ênfase na formação de recursos humanos para que o computador fosse introduzido como instrumento de ensino de maneira adequada. A partir de 1986, outros projetos foram incorporados ao Educon, enquanto outros se desligavam dele. O Formar foi um desses projetos que se incorporaram ao Educon.

Fruto de uma iniciativa do Programa de Ação Imediata em Informática na Educação de $1^{\circ}$ e $2^{\circ}$ graus, desenvolvida pela UNICAMP em 1986, o projeto Formar era voltado especificamente para formar recursos humanos para o trabalho na área da informática educativa; objetivava-se formar professores críticos na área da informática educacional. Para isso, foram desenvolvidos cursos de especialização para pessoas de diferentes estados que, ao final da capacitação, exerceriam o papel de multiplicadores da informática nas escolas públicas em sua região de origem. Com isso, assumiram o compromisso de estruturar e implementar os Centros de Informática Educativa (CIED) em parceria com as Secretarias de Educação de suas respectivas cidades. A criação dos centros foi a primeira experiência de descentralização das decisões federais, ao permitir que cada Estado fosse o responsável pelo programa e seu desenvolvimento. Foram 17 CIED implantados nos anos de 88 e 89, em 17 estados brasileiros, chegando em 1997 a 20.

Em outubro de 1989, através da Portaria Ministerial n. ${ }^{\circ}$ 549/GM e com base no Educon e nos projetos decorrentes dele, o governo federal, por meio do MEC, lançou o Proninfe. Dando continuidade as propostas anteriores, seu objetivo se concentrava na contínua capacitação dos professores e sua finalidade era a de, no Brasil, por meio de projetos e atividades, desenvolver a informática educativa amparada em fundamentação pedagógica atualizada e sólida, a fim de assegurar o êxito dos investimentos e esforços envolvidos na sua criação. De acordo com Maia e Barreto (2012), este programa fomentou sobremaneira, nas escolas públicas do País, a criação de laboratórios de informática educativa (LIE). Foram criados núcleos e laboratórios de formação de professores dos três graus (fundamental, médio e superior), bem como na área da educação especial e em nível de pós-graduação. Os núcleos eram distribuídos geograficamente por todo país, possuindo um modelo descentralizado. Além da capacitação dos professores, suas atividades se concentravam na capacitação de técnicos dos diferentes sistemas de ensino, no desenvolvimento de pesquisa básica e aplicada, na implementação de centros de informática educativa e na produção, aquisição, avaliação e adaptação de softwares educativos.

As diversas experiências anteriores e toda a sua construção são os motivos que deram base e possibilitaram a criação de outro programa relacionado à informática educativa, o ProInfo - Programa Nacional de Informática na Educação. Lançado em abril de 1997, pela Portaria n. ${ }^{\circ} 522$ e posteriormente reeditada por meio do Decreto n. ${ }^{\circ} 6.300$ de 12 de dezembro de 2007, 
quase 10 anos após o Proninfe, pela Secretaria de Educação a Distância (Seed / MEC), cria-se o ProInfo com o objetivo de dar suporte e promover a inserção do uso pedagógico da tecnologia informática na rede pública de educação básica e com a intenção de formar milhares de professores e atender milhões de estudantes, por meio de aquisições de computadores interligados à internet. Conforme aponta Borba e Penteado (2017), desde o seu lançamento, o programa equipou mais de 2000 escolas e investiu na formação de milhares de professores por meio dos Núcleos de Tecnologia Educacional (NTE), instalados em diversos países. Ressalta-se que as ambiciosas metas deste programa só foram possíveis ser estabelecidas como metas graças à cultura existente, gerada em função da competência, criatividade e capacidade de resistência e sobrevivência dos profissionais das universidades e das secretarias de educação, que desenvolveram pesquisas e implementaram projetos contextualizados voltados para os interesses e as necessidades da comunidade.

A criação do ProInfo, bem como de suas metas e diretrizes foram articuladas entre diversas equipes da esfera governamental: SEED/MEC, o Conselho Nacional de Secretarias Estaduais da Educação (CONSED) e comissões estaduais de informática na educação, com representação dos municípios, da comunidade em geral e das universidades. A adesão ao ProInfo dependia de o Estado possuir um Programa Estadual de Informática na Educação, pois seria ele o responsável por garantir a formação dos professores, o espaço físico para instalação dos equipamentos e manutenção técnica.

Desde a concepção do programa, a capacitação de recursos humanos tem destaque em suas intenções. O princípio adotado na formação do professor é o de professores multiplicadores que são preparados em cursos especialmente planejados para capacitá-los a organizar e dinamizar atividades de formação para seus pares. Levam-se em conta, nessas ações, as características regionais. Tavares (2002, p. 10) destaca que, a atenção atribuída à capacitação dos professores no ProInfo não visava "apenas prepará-los para usar as novas tecnologias da informática como ferramenta de apoio ao processo ensinoaprendizagem, mas criar uma consciência crítica sobre sua utilidade e utilização educacional”.

Embora seja um programa inovador, com a criação dos NTE, com a ampliação da rede de multiplicação de conhecimento, com a maior abrangência de capacitação de recursos humanos e com a distribuição de equipamentos e acesso à internet, tem-se que o ProInfo foi alvo de algumas críticas ao seu complexo modelo. Tavares (2002) ressalta uma delas: o fato de o programa deixar a cargo da escola a criação de projetos envolvendo a informática educacional. Porém, como fazer isso se ela não está preparada para a sua elaboração? Pimentel (2012) salienta como crítica às políticas públicas de inserção das tecnologias digitais no ambiente escolar o desafio de irem além dos indicadores quantitativos. Cabe destacar que, embora tenham ocorridos avanços, conforme mostra o panorama histórico exposto anteriormente, os investimentos ficaram mais centralizados na aquisição e no acesso aos equipamentos tecnológicos, ao não enfatizar a importância da inovação das práticas pedagógicas; fator este que também ocorreu em outros países considerados mais desenvolvidos, conforme aponta Valente e Almeida (1997). Caso a integração das TICs nas escolas não leve em consideração que a inovação tecnológica deve ser acompanhada pela inovação das práticas pedagógicas, não se alterará substancialmente a natureza das práticas culturais das escolas, tornando a sua integração uma "mera mudança superficial dos recursos escolares” (Pimentel, 2012, p. 98). Desde o início do milênio, Kenski (2003, p. 15) defendia que apenas incluir recursos tecnológicos na escola não garante uma mudança no desempenho dos alunos. É necessário, para que se tenha um melhor ensino, que se façam "reformas estruturais na organização da escola e no trabalho docente".

Uma das fortes críticas que não se restringe apenas ao ProInfo, mas a todos os projetos que o antecederam é com relação à formação de professores. Apesar de a formação de capital humano ser foco de todos os programas governamentais, alguns autores como Maia e Barreto (2002) sinalizam que a ênfase dos programas recaiu muito mais na disponibilidade de softwares e aparelhos tecnológicos do que na formação do professor para o trabalho pedagógico com as tecnologias digitais, conforme pretensões iniciais. Valente $(1999$, p. 12) destaca o processo lento e frágil da formação de professores por meio dos programas governamentais e aponta o desequilíbrio e atropelo que o processo de formação sofreu perante os avanços 
tecnológicos, "fazendo com que o professor sinta-se eternamente no estado de "principiante" em relação ao uso do computador na educação". Desde as primeiras experiências com a informática educativa, o autor já afirmava que são necessários quatro elementos básicos para a sua implantação na educação: o computador, os softwares educativos, os alunos e os professores; sendo este último elemento determinante para o sucesso da nova prática educativa, uma vez que a condução da incorporação dos recursos tecnológicos no processo de aprendizagem dos alunos é dada pelos professores.

Com relação aos desafios colocados ao professor quando os computadores chegaram às escolas nas décadas de 80 e 90, Turin, Henrique e Bairral (2018, p. 69-70) apontam que continuam presentes nos dias de hoje e destacam ainda dois pontos importantes no que se refere às políticas públicas para o uso das tecnologias na educação, a saber: numa esfera micro, para que sejam efetivas as práticas pedagógicas com as TIC são necessárias mudanças pontuais que não dependam apenas da aquisição de equipamentos, mas, dentre outros fatores, de uma formação continuada docente com foco nos múltiplos letramentos, levando sempre em consideração “as peculiaridades regionais e da própria escola”. Numa esfera macro,

observamos que políticas que visam ampliar o acesso e a democratização do ensino nem sempre atende as demandas populares, pois interesses do capital são colocados como forma de moldar e colocar a sociedade a serviço do próprio capital mantendo a lógica vigente. Dessa forma, destacamos a necessidade de superar a ideia de que apenas o acesso às tecnologias garante avanços e melhorias no ambiente educacional. (Turin, Henrique \& Bairral, 2018, p. 70).

Ferreira e Bueno (2014, p. 104) apresentaram uma análise crítica sobre o que denominam por "projetos compensatórios na educação", sendo o ProInfo um deles. Os autores analisaram projetos educacionais presentes em escolas públicas brasileiras na perspectiva de descortinar o discurso neoliberal empregado na construção da excelência da educação. Suas críticas vão ao encontro das reflexões de que tais projetos "contribuem para alicerçar as ideias dos imperativos mercadológicos do capital". De acordo com os autores, projetos como o ProInfo têm sido vistos como parte essencial do discurso da qualidade da educação, sustentado por meio de uma gestão democrática, gerando “o sentimento de que a participação coletiva na escola se efetiva por meio da execução e implantação desses projetos, que constroem pseudodecisões acrescentadas no cerne da escola" (Ferreira \& Bueno, 2014, p. 112). As reflexões realizadas por Ferreira e Bueno (2014, p. 113) conduzem ao entendimento de que os projetos educacionais e o pensamento pedagógico relacionado à autonomia e à gestão escolar são "elementos da perfeita crença mistificada de que neles se encontram a solução para os problemas da realidade educacional brasileira”. Os autores, com isso, põem em discussão a origem na prática capitalista de projetos como o ProInfo e atribui a eles um lugar de paliativo no processo de mitigação dos problemas educacionais, quando o discurso é a qualidade da educação.

As críticas supracitadas são de fundamentais relevâncias, mas não extinguem o fato de que os projetos apresentados geraram e ainda geram frutos em algumas escolas públicas brasileiras, quando o assunto é a inserção da informática na escola. Em 1999, Valente já ressaltava, no sentido da mudança pedagógica necessária a implantação da informática na escola, que, embora sejam modestos os resultados dos projetos governamentais, eles têm sido coerentes e sistematicamente têm enfatizado a mudança na escola. Além disso, em meio a tudo o que foi posto até então, observa-se que existiu um movimento crescente dos órgãos governamentais no sentido de inserir o computador nas escolas. Como todo projeto, nota-se também que não há neutralidade política, econômica, mercadológica e social neles e, nesse sentido, apontam algumas das críticas apresentadas anteriormente. Ressalta-se ainda que, houve momentos na história cujo cancelamento de verbas afetou diretamente a continuação de determinados projetos e programas. Por exemplo, conforme citam Borba e Penteado (2017) numa crítica à influência política na continuidade de programas educacionais como os já citados, na década de 80 alguns CIED deixaram de receber apoio do governo federal, estagnando a capacitação dos professores nos casos em que o governo estadual não assumiu 
os gastos. Como há tempos dizia Freire: "O problema é que as escolas estão sempre muito atrasadas com relação ao uso da tecnologia, dos instrumentos, por $N$ razões, até por falta de verba, em países como o nosso" (Freire \& Guimarães, 2011, p. 72).

Castells (2019) descreve que a tecnologia não determina a sociedade e nem a sociedade escreve o curso da transformação tecnológica, dado que muitos outros fatores, como a iniciativa empreendedora e a criatividade, intervêm no processo de descoberta científica, inovação tecnológica e aplicações sociais, de maneira que o resultado final se torna dependente de uma complexa rede interativa. Entretanto, embora não determine a tecnologia, o autor aponta que a sociedade pode sufocar seu desenvolvimento principalmente por intermédio do Estado. Indubitavelmente, a habilidade ou inabilidade de as sociedades dominarem a tecnologia e, em especial, as que são decisivas em cada período histórico, traça o seu destino a ponto de a sua presença (ou mesmo falta) determinar a capacidade de transformação das sociedades, bem como os usos que as sociedades decidem atribuir ao seu potencial tecnológico.

Mesmo com algumas das críticas expostas, não há como abster-se do fato de que, conforme aponta Tavares (2002), os projetos citados possuem valiosas iniciativas na área da informática educacional. Mas, alguns apontamentos ainda carecem atenção. Borba e Penteado (2017, p. 23) nos apresentam alguns deles, a saber: existe um crescente interesse e envolvimento de coordenadores e diretores para a área da informática educativa em suas escolas. Porém, destaca os autores que, “essas ações atendem a um número bastante reduzido de escolas, além de que o suprimento técnico, embora fundamental, não é garantia de uso dentro dos padrões esperados”. Outro ponto de atenção é a forma como a informática educativa é coordenada nas escolas. Os autores destacam que existem escolas onde há uma subutilização da sala de informática ou, conforme cita Silva (2011, p. 31), "as salas de recursos audiovisuais são verdadeiros sarcófagos na maioria das escolas", por diferentes motivos como a excessiva normatização para o uso dos equipamentos, o amedrontamento por meio da responsabilização do professor pelo dano causado às máquinas durante a sua aula e a ausência de treinamento dos professores na utilização dos equipamentos que a compõe. Nesse caminho, essa utilização inadequada das salas / laboratórios de informática evidenciam a falta de planejamento pedagógico e administrativo para a inserção dos computadores nas práticas educativas. Há também as dificuldades estruturais das salas de informática, a carência de técnico de informática para dar suporte aos aparelhos que compõem o ambiente, a dificuldade no acesso à internet, a falta de aparelhos atualizados, entre tantos outros limitantes oriundos dos projetos citados que compõe o histórico da informática educacional no Brasil.

Tendo sido apresentado um histórico a respeito dos programas governamentais de fomento à informática na educação, traçado reflexões e posto algumas críticas direcionadas a eles, resta-nos descortinarmos alguns dos atuais projetos de pesquisa da área da tecnologia na educação. Afinal de contas... a que pontos chegamos?

\section{Onde o Caminho nos Levou: A que Ponto Chegamos!}

De acordo com as fases das tecnologias estabelecidas por Borba, Silva e Gadanidis (2018), a maioria dos programas governamentais citados anteriormente nascem nas chamadas três primeiras fases das tecnologias digitais, cujos elementos principais são os laboratórios de informática, o software Logo, os computadores pessoais e a internet. Impulsionada pela velocidade de navegação na internet, em meados de 2004, dar-se início a quarta fase das tecnologias. Com ela, ganham-se fôlegos termos como tecnologias digitais e pesquisas relativas a outros aparelhos tecnológicos digitais, como os tablets e os smartphones.

A inclusão digital dos estudantes não se extinguiu na entrada dos computadores no ambiente educacional, nem mesmo na criação de laboratórios de informática provenientes dos programas governamentais que fomentam a necessária presença das tecnologias nas salas de aula. Durante o Fórum Econômico Mundial em Davos, na Suiça, ocorrido no ano de 2005, o projeto 
One Laptop per Child ${ }^{2}$ (OLPC) foi apresentado ao governo brasileiro. Em junho de 2005, interessado pela ideia do projeto da Suiça, o governo brasileiro criou uma rede ministerial para tratar do assunto no País (Brasil, 2012). Surge, então, em 2007, o pré-piloto do Projeto denominado Um Computador por Aluno, que se prestava atender cinco escolas púbicas brasileiras, coordenado pela Secretaria de Educação a Distância (SEED) do MEC. Sustentava-se a ideia, por meio do governo, de que a disseminação do laptop educacional com acesso à internet seria uma poderosa ferramenta de inclusão digital e melhoria da qualidade do ensino. Esse projeto inicial atingiu os estados de São Paulo, Rio de Janeiro, Rio Grande do Sul, Tocantins e Distrito Federal (Andriola \& Gomes, 2017).

Com o lançamento da Medida Provisória 472 de 2009, o projeto ganhou status de Programa Um Computador por Aluno (PROUCA), sendo convertida na Lei $\mathrm{n}^{\circ}$ 12.249/2009, em 14 de junho de 2010, com o objetivo disposto em seu artigo $7^{\circ}$ :

Promover a inclusão digital nas escolas das redes públicas de ensino federal, estadual, distrital, municipal ou nas escolas sem fins lucrativos de atendimento a pessoas com deficiência, mediante a aquisição e a utilização de soluções de informática, constituídas de equipamentos de informática, de programas de computador (software) neles instalados e de suporte e assistência técnica necessários ao seu funcionamento.

Esta Lei além de regulamentar o PROUCA, instituiu o Regime Especial de Aquisição de Computadores para Uso Educacional (RECOMPE) que trata das formas de aquisição dos laptops educacionais pelo Governo Federal. Com isso, foram atendidas aproximadamente 300 escolas públicas estaduais e municipais brasileiras, distribuídas nas 27 unidades da Federação, com a distribuição por volta de 150.000 computadores portáteis educacionais. O critério de seleção das escolas contempladas pelo PROUCA atendia a dois principais pontos: a infraestrutura da escola e o compromisso de uma política de formação dos professores e gestores para dinamizar os processos dessa fase do projeto. Conforme projetos anteriores, estruturou-se a política de formação de professores multiplicadores do PROUCA, responsáveis pela sua disseminação. Foram convocados para esta fase as instituições de ensino superior, as secretarias de educação e os NTE criados pelo Proninfe (Maia \& Barreto, 2012).

Em uma análise bibliométrica realizada por Andriola e Gomes (2017) foi possível identificar 43 teses e dissertações produzidas no Brasil acerca do PROUCA, no período de 2008 a 2014, presentes no banco de teses da CAPES e na Biblioteca Digital Brasileira de Teses e Dissertações. Processos de Ensino/Aprendizagem, prática docente, formação de professores e tecnologias digitais na educação são as temáticas de maior recorrência entre as teses e dissertações pesquisadas. De acordo com os autores, os estudos realizados evidenciaram as potencialidades do PROUCA, mas também apontaram falhas no processo de implantação, formação, apropriação tecnológica e uso pedagógico do laptop educacional. Os resultados da pesquisa ainda permitiram elencar os aspectos positivos e negativos do PROUCA. Dentre os pontos positivos, destacam-se os significativos avanços no processo de inclusão digital, o uso instrumental das tecnologias digitais pelos professores e alunos e o incentivo à cultura colaborativa da construção do conhecimento. Dentre os pontos negativos, têm-se os problemas de infraestrutura das escolas do PROUCA (instalações e rede elétrica, ineficiência da rede de internet e inadequações do local de armazenamento dos equipamentos), a subutilização dos recursos pedagógicos disponibilizados pelos laptops, ausência de suporte técnico, não reposição de equipamentos e a descontinuidade do processo de formação de professores.

Em anúncio realizado em fevereiro de 2012, o governo federal, por meio do MEC, no final de 2011 lançou edital para licitar a compra de aproximadamente 600.000 tablets para serem distribuídos em quase 58.000 escolas públicas brasileiras da educação básica. A ideia inicial era entregar os tablets a professores e alunos, conforme ocorreu no PROUCA com os laptops. Contudo, com o entendimento do MEC de que o professor deve ser o primeiro a estar familiarizado com os recursos na prática

2 Trata-se de um projeto produzido por uma Instituição sem fins lucrativos, cujo objetivo foi a inclusão digital escolar, proporcionando a cada estudante um computador portátil de custo reduzido (Maia \& Barreto, 2012). 
pedagógica, o projeto inicialmente contemplou apenas professores do ensino médio de escolas públicas federais, estaduais e municipais que já possuíam internet de alta velocidade. Dá-se início, com isso, a inserção dos tablets nas escolas públicas brasileiras por meio, inicialmente, dos professores e com ele as muitas críticas com relação à qualidade do aparelho e do acesso à internet (Pimentel, 2012).

Nota-se, portanto, a partir do inventário apresentado que, desde a década de 1990, estudos e programas governamentais vem sendo propagados no Brasil sobre o incentivo ao uso das tecnologias digitais na educação. Há nisso uma evolução dos aparelhos que protagonizaram estas discussões: inicialmente, os computadores pessoais, com a premissa dos laboratórios de informática; posteriormente, os laptops e computadores portáteis; até a chegada dos tablets nas escolas públicas brasileiras. Cabe ressaltar que estamos apresentando apenas um recorte dessas fases das tecnologias, uma vez que pode ser atrelado aos aparelhos citados até aqui outros protagonistas como, por exemplo, o rádio e a televisão educativa. Silva (2011, p. 31) faz uma crítica nesse sentido ao tratar sobre metodologias de ensino e ao fazer uso do termo modismo ao citar, por exemplo, os laboratórios de informática: "Essas 'coisas' iam sendo adotadas à medida que iam surgindo no mercado. A simples 'fama` da técnica em países diferentes do nosso já era suficiente para garantir a sua eficácia”.

Borba e Lacerda (2015), ao analisar algumas políticas públicas referentes às tecnologias digitais na educação propõe, a partir do PROUCA, o projeto Um Celular por Aluno, como forma de incorporar os celulares inteligentes com internet às salas de aula. Apesar de não se ter em nível nacional um programa governamental que ofereça aos alunos smartphone para que seja utilizado com fins educacionais, esse esboço de projeto apresentado no III Fórum de Discussão: Parâmetros Balizadores da Pesquisa em Educação Matemática no Brasil, pelos pesquisadores Borba e Lacerda (2015), propõe que as tecnologias não fiquem isoladas da sala de aula, conforme ocorria com os computadores no laboratório, mas que sejam incorporadas dentro da dinâmica dela. Os laboratórios de informática, neste sentido, são vistos como uma extensão da sala de aula, contudo não fazendo parte dela, o que caracteriza estes espaços como uma adoção limitada das tecnologias digitais na educação, diferentemente dos dispositivos móveis que podem fazer parte da sala de aula do estudante. Na figura 1 elencamos os aparelhos tecnológicos que protagonizaram o caminho das tecnologias educacionais apresentado até aqui.

Figura 1: Aparelhos protagonistas nos programas / projetos citados

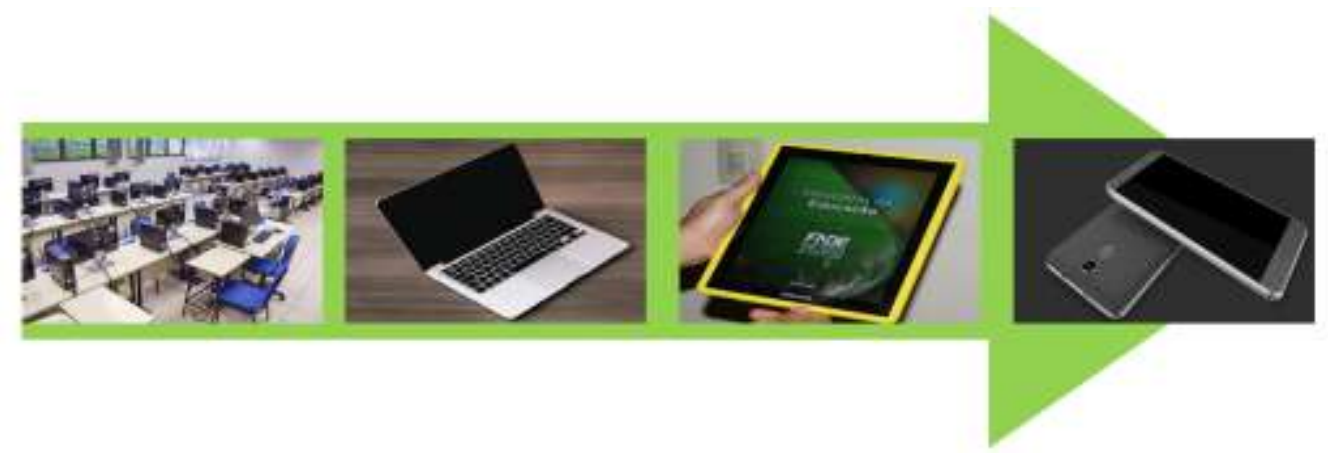

Fonte: Autores (2021).

Ao estudar o uso do celular inteligente como ferramenta pedagógica na sala de aula e fora dela, Moura (2010) indicou que a incorporação desses aparelhos pelos alunos em seus estudos é dada de forma natural, explorando as várias funcionalidades em diferentes atividades curriculares, individual ou coletivamente, dentro ou fora da sala de aula. Numa pesquisa sobre as formas de emprego dos celulares nas escolas, Nagumo e Teles (2016) elaboraram quatro categorizações explanatórias de seu uso na escola por estudantes: regras, uso didático, motivação e consequências. A primeira se refere às leis de proibição e às restrições ou proibições impostas pela própria escola e professores. A segunda trata do uso didático dos 
celulares no ambiente educacional. Os autores afirmam que, "enquanto os alunos de hoje convivem com diversos dispositivos eletrônicos e digitais, a escola continua obstinadamente arraigada em seus métodos e linguagens analógicos" (Naguno \& Teles, 2016, p. 364). As duas últimas categorias tratam, respectivamente, da motivação dos estudantes com relação ao uso de celulares - sendo destaque dos autores a questão do tédio e o uso das redes sociais como motivadores - e das consequências do uso em sala de aula, problematizando as questões de "cola", privacidade e distração. A partir da análise dessas categorias, Nagumo e Teles (2016) notaram que, em geral, a proibição tende a ser o caminho das escolas para o uso de celulares, porém os estudantes costumam transgredir tal proibição em virtude do tédio das aulas ou dos tempos livres.

$\mathrm{Na}$ incorporação das tecnologias digitais nas salas de aula, Borba, Silva e Gadanidis (2018, p. 84) discutem maneiras de que isto ocorra sem que haja a necessidade de compras de computadores, mas sim de banda larga. Nesse caminho, os autores são "a favor do uso de celulares em sala de aula, embora os limites e formas de uso tenham que ser discutidos". Fato é que a utilização desta tecnologia digital foi e é ainda palco de muitas discussões e controvérsias. Enquanto pesquisadores como os citados defendem a sua inserção em sala de aula, outros a abominam e reconhecem tais aparelhos como um dos principais responsáveis pela falta de atenção dos alunos nas aulas; atrelam-se a estes as leis de proibição ${ }^{3}$ do uso de celulares em sala de aula e o veto a projetos que visam distribuir internet gratuitamente para estudantes e professores da rede pública de ensino. Porém, corroboramos com a contundente afirmação de Borba e Lacerda (2015, p. 504) que diz: "Não cabe mais discutir se os celulares serão ou não utilizados na sala de aula. Eles já estão lá! Queiramos ou não", especialmente em tempos de pandemia ocasionada pelo COVID-19, e de Romanello (2016, p 123) em sua dissertação sobre a utilização de celulares inteligentes no desenvolvimento de conceitos matemáticos em sala de aula: "Celular na sala de aula: é possível? Esta pesquisa vem ao encontro dessa pergunta para dizer que: Sim, é possível!"”.

Não há que se negar que os smartphones são vistos como uma extensão de nosso corpo e que durante a pandemia ele se tornou um recurso indispensável para estudantes e professores em atividades remotas, revelando mazelas e intensificando desigualdades. Nesse caminho, apesar da carência de uma proposta nacional nesse sentido, há diversas pesquisas a respeito da utilização das tecnologias digitais móveis, em especial os smartphones, na Educação Matemática. Sobre elas que trataremos um pouco mais aqui na intenção de apresentarmos as atuais pesquisas que integram a quarta fase das tecnologias na educação. Na busca por pesquisas nacionais relativas ao tema, encontramos nos anais do Encontro Brasileiro de Estudantes de PósGraduação em Educação Matemática (EBRAPEM) a possibilidade de descortinarmos as atuais tendências de pesquisa na área, conforme descrevemos na metodologia da pesquisa.

Foram analisados todos os anais que compõe o grupo de discussão 6 (GD 6) do referido evento, que se destina à pesquisa em Educação Matemática, tecnologias digitais e educação a distância, no período de 2014 a 2019 , respectivamente, do XVIII ao XXIII EBRAPEM. No quadro 3 apresentamos os dois pesquisadores que mais se destacaram nesta investigação, a partir da catalogação realizada levando em consideração os artigos e as referências utilizadas por cada artigo que compôs nossa consulta foram: Marcelo Almeida Bairral, da Universidade Federal Rural do Rio de Janeiro (UFRRJ) e Marcelo de Carvalho Borba, da Universidade Estadual Paulista Júlio de Mesquita Filho (UNESP); que, inclusive, são também coordenadores do GD 6. Por meio do currículo lattes dos pesquisadores, foi possível sintetizar suas formações no Quadro 3.

\footnotetext{
${ }^{3}$ Há leis municipais e estaduais que determinam a proibição ao uso de aparelhos eletrônicos por alunos na escola e/ou na sala de aula. Para compreender melhor isso, foi realizado um levantamento na internet com termos "lei", "celular" e "escola". Foram levantadas e analisadas 23 leis, sendo 11 estaduais, 11 municipais e uma do Distrito Federal. Todas foram publicadas entre 2002 a 2012. Em geral, as leis analisadas focam na proibição ao uso do celular pelos alunos nos estabelecimentos escolares ou na sala de aula; ressaltam a importância de que a comunidade escolar tenha conhecimento dessas leis; e determinam diretrizes para a escola lidar com os alunos que as descumprirem (Naguno \& Teles, 2016, p. 363).
} 
Quadro 3: Pesquisadores Bairral e Borba.

\begin{tabular}{||l||l|l|}
\hline É professor titular da Universidade Federal Rural do Rio de Janeiro. Licenciado (1990) e especialista (1992) em \\
Matemática pela Universidade Federal Fluminense, mestre em Educação Matemática pela Universidade Santa \\
Úrsula (1996), doutor em Educação Matemática pela Universidade de Barcelona (2002) e pós-doutor em \\
Educação Matemática pela Universidade do Estado de Nova Jersey (EUA, 2007) e pela Universidade de Turin \\
(Itália, 2012). Preside o Gepem desde 2003 e é o editor responsável do Boletim Gepem. Fundador (em 1999) e \\
coordenador do Grupo de Estudos e Pesquisas da TIC em Educação Matemática (www.gepeticem.ufrrj.br). \\
Idealizador e coordenador da Série InovaComTic da Editora da UFRRJ (Edur). \\
\hline $\begin{array}{l}\text { Licenciado em Matemática pela UFRJ, mestre em Educação Matemática pela UNESP, Rio Claro, SP, e doutor } \\
\text { nessa mesma área pela Cornell University, Estados Unidos. Em 2005 se tornou livre docente em Educação } \\
\text { Matemática. É professor do Programa de Pós-Graduação em Educação Matemática da UNESP, Rio Claro, SP, } \\
\text { programa do qual foi coordenador por mais de seis anos. Coordenador do Grupo de Pesquisa em Informática, } \\
\text { Outras Mídias e Educação Matemática (GPIMEM), desenvolve pesquisas nas áreas de EaD online, Modelagem, } \\
\text { Tecnologias Digitais, Vídeos e Metodologia de Pesquisa Qualitativa. }\end{array}$ \\
\hline
\end{tabular}

Fonte: Autores (2021).

Dos três projetos de pesquisa ${ }^{4}$ que integram o arsenal teórico-metodológico discutido por Bairral, as práticas educativas e discussões em Educação Matemática com dispositivos touchscreen são as que se mostraram com maior frequência nas produções do evento, cujo assunto matemático em voga é a geometria (Settimy, 2018; Lacerda, 2017; Oliveira, 2017; Duarte, 2017; Marques, 2017; Assis, 2016; Henrique, 2016). O uso de smartphones e tablets são os dispositivos que ganham destaque nas pesquisas, cujo foco dos estudos é analisar "o aprendizado matemático em dispositivos com manipulação touchscreen" (Bairral, Assis \& Silva, 2015, p. 15) e associar o pensamento matemático a uma nova forma de expressão gestual: o touchscreen; utilizando, para isso, contribuições de diferentes áreas do conhecimento como a Educação Matemática, a educação, a neurociência e a psicologia cognitiva. A geometria é a área da matemática mais citada nos artigos pesquisados, uma vez que o grupo de pesquisa coordenado por Bairral abriu uma agenda de investigação destinada à educação geométrica, com dispositivos dinâmicos touchscreen, com interesse não só nos movimentos matemáticos mais conhecidos (transladar, girar, etc.), mas também nos “modos de manipulação touchscreen e na identificação de estratégias de raciocínio dos discentes que podem estar associadas aos diferentes modos de tocar em uma tela” (Bairral, Assis \& Silva, 2015, p. 17).

Já os artigos presentes no EBRAPEM que possuem Borba como orientador e os trabalhos que o referencia são oriundos de pesquisas vinculadas ao Grupo de Pesquisa em Informática, outras Mídias e Educação Matemática - GPIMEM ${ }^{5}$ e

\footnotetext{
${ }^{4}$ Construindo e analisando práticas educativas em Educação Matemática com dispositivos touchscreen; Participar, descobrir e interagir em ambientes virtuais: Potencializando novas formas de aprendizagem matemática; e Materiais Curriculares Educativos Online (MCEO): Elaboração, disponibilização e análise de aprendizagem.

${ }^{5}$ A Educação Matemática - embora seja possível encontrar passos iniciais no sentido da formação de um novo campo de estudo, no início da década de 1970 - ganha força a partir da criação do PPGEM e de outros programas de pós-graduação (BICUDO, 1999; D’AMBRÓSIO; BORBA, 2010), principalmente em virtude de serem locais comuns a diversos pesquisadores preocupados com questões inicialmente relacionadas ao ensino e à aprendizagem de Matemática, o que favoreceu, por sua vez, a criação e fortificação de Grupos de Pesquisa vinculados a esses programas. Um destes grupos é o Grupo de Pesquisa em Informática, outras Mídias e Educação Matemática (GPIMEM), cujo objetivo é estudar questões ligadas às tecnologias na Educação Matemática, em particular o uso das Tecnologias Digitais (TD) na formação do professor de Matemática, na sua atuação em sala de aula ou, ainda, na maneira com que os alunos modificam seu pensamento a partir do contato com estas tecnologias. (Borba, Almeida \& Chiari, 2015, p. 1117-1118). O GPIMEM está disponível na internet através do endereço eletrônico: http://www.rc.unesp.br/gpimem/index.php. Acesso em 02 abr. 2021.
} 
envolvem assuntos diversos sobre tecnologias digitais e Educação atemática, destacando-se a produção de vídeos (Domingues, 2016; Oechsler, 2016; Oliveira, 2016; Silva, 2016; Fontes, 2017; Neves, 2018; Souza, 2018; Carvalho, 2019; Stal, 2019), mais especificamente, as PMDs como produção de vídeos (Gregorutti, 2015; Vital, 2016; Stivam, 2018; Gimenez, 2019) na Educação Matemática. Nesse sentido, apresentaremos a seguir os projetos de pesquisa que estão relacionados à temática das PMDs, cumprindo, assim, o objetivo que foi traçado para este artigo: apresentar, a partir de uma das temáticas que o assunto PMD envolve - tecnologias digitais - uma breve trajetória que se inicia com a entrada da tecnologia informática nas escolas brasileiras até os mais atuais projetos que envolvem discussões das tecnologias digitais com artes e Educação Matemática, através das PMDs.

Coordenado por Borba e Gadanidis, Digital Mathematical Performance (2006 - 2008) foi o primeiro projeto de pesquisa sobre o tema. Financiado pela agência de fomento canadense Social Sciences and Humanities Council of Canada (SSHRC), o projeto teve duração de 36 meses e, a partir dele, objetos virtuais foram criados, com designs diferentes concebidos em programação flash (Borba, Silva \& Gadanidis, 2018).

Flatland é um exemplo de PMD produzida no primeiro projeto. A partir do tema "paralelismo sobre esferas", foram criadas poesias, músicas, videoclipes, demonstrações visuais, atividades de ensino e aprendizagem com estudantes e diversos modos de comunicar essa ideia matemática utilizando expressões artísticas. Além disso, o conteúdo matemático envolvendo paralelismo sobre esferas torna-se bastante interessante quando trabalhado dessa maneira. (Borba, Silva \& Gadanidis, 2018, p. 112).

Borba et al. (2009, p. 2) já vinham "atribuindo significados diversos à palavra performance ${ }^{6}$ além daqueles tradicionalmente atribuídos em educação, os quais nos trazem entendimentos sobre avaliação, desempenho escolar”, muito por conta do envolvimento dos principais autores do projeto em modalidades artísticas. Tais autores, já vinham também argumentando sobre o modo como as mídias moldam a performance em seus múltiplos significados:

(i) a produção de conhecimentos matemáticos em contextos pedagógicos (BORBA; VILLARREAL, 2005; SCUCUGLIA, 2006); (ii) o design de significados e conhecimentos de caráter linguísticos quando enfocamos, por exemplo, o modo como poesias digitais são investigadas e/ou criadas (HUGHES, 2003). Nesse sentido, iniciamos o desenvolvimento de um projeto articulando estas idéias e tendências (GADANIDIS, 2006). (Borba et al., 2009, p. 2).

Esse projeto deu vida a um novo projeto intitulado Students as Performance Mathematicians (2008 - 2011), numa parceria internacional de cinco integrantes: Gadanidis, da University Western Ontario (UWO); Borba (UNESP); Gerofsky, da University of British Columbia (UBC); Hoogland (UWO) e Hughes, da University of Ontario Institute of Technology (UOIT), além de três assistentes: Scucuglia (UNESP), Tolley (UOIT) e Wiebe (UWO) (Domingues, 2020).

Com financiamento da SSHRC, os projetos seguintes objetivaram "oferecer a professores e estudantes de diversos níveis de ensino a oportunidade de produzir suas próprias PMD, tanto no Brasil como no Canadá” (Borba, Silva \& Gadanidis, 2018, p. 115) e proporcionaram "um olhar para a Educação Matemática por meio de lentes performáticas e artísticas, com o objetivo de modificar a Imagem Pública da Matemática” (Domingues, 2020, p 17). No quadro 4 apresentamos uma síntese dos projetos supracitados e de outros que os sucederam sobre PMDs.

\footnotetext{
6 "Subir ao palco, recitar ou declamar poesias, tocar guitarra, ou encenar uma peça teatral, são ações que nos fazem atribuir significados diversificados a palavra performance" (Borba et al., 2009, p. 2).
} 
Quadro 4: Descrição dos projetos sobre PMDs.

\begin{tabular}{|c|c|}
\hline Projeto & Breve descrição \\
\hline $\begin{array}{l}\text { Digital Mathematical Performance } \\
\qquad(2006 \text { - 2008) } \\
\text { https://www.edu.uwo.ca/dmp/ }\end{array}$ & $\begin{array}{l}\text { Apresenta vinte PMD produzidas por Gadanidis e Borba. Os designs dessas PMD são } \\
\text { variados, vão desde vídeos singulares até objetos virtuais envolvendo múltiplos links para } \\
\text { vídeos, textos e simulações em flash. Os vídeos incluem entrevistas com professores e } \\
\text { pesquisadores, performance em salas de aula, videoclipes musicais, performances cênicas } \\
\text { em photo-story (slideshow) e storytelling digital, sessões com estudantes, etc. }\end{array}$ \\
\hline $\begin{array}{l}\text { Students as Performance Mathematicians } \\
\qquad(2008-2011) \\
\text { https://www.edu.uwo.ca/mpc/students.html }\end{array}$ & $\begin{array}{l}\text { Através desse projeto, os pesquisadores envolvidos coordenaram atividades em escolas no } \\
\text { Brasil e no Canadá nos quais estudantes do ensino fundamental, familiares, professores e } \\
\text { artistas profissionais criaram PMD colaborativamente. Além disso, foram realizados } \\
\text { festivais matemáticos nas escolas para que as performances criadas fossem exibidas } \\
\text { publicamente. }\end{array}$ \\
\hline $\begin{array}{c}\text { Math }+ \text { Science Performance Festival } \\
(2008 \text { - atual) } \\
\text { http://www.mathfest.ca/ }\end{array}$ & $\begin{array}{l}\text { A cada ano, no site desse projeto, pode-se submeter PMD. As PMD são publicadas e uma } \\
\text { equipe de jurados composta por artistas profissionais, matemáticos e educadores indica suas } \\
\text { PMD favoritas, baseando-se em três critérios: (a) profundidade da ideia matemática; (b) } \\
\text { criatividade e imaginação e (c) qualidade artística e tecnológica. Os autores das PMD } \\
\text { indicadas são premiados com medalhas confeccionadas pelo Fields Institute - a Sociedade } \\
\text { Canadense de Matemática - pela Western University e pela ESSO Imperial Oil. }\end{array}$ \\
\hline $\begin{array}{l}\text { Performing Reserch Ideas } \\
\text { (2011 - 2013) } \\
\text { https://imaginethis.ca/ }\end{array}$ & $\begin{array}{l}\text { A partir desse projeto são produzidos documentários digitais sobre atividades em sala nos } \\
\text { quais estudantes utilizam as artes para explorar ideias matemáticas. O foco é oferecer a } \\
\text { estudantes e professores do ensino fundamental a oportunidade de produzir PMD e, } \\
\text { recursivamente, disseminar os resultados de pesquisa em formato digital, de um ponto de } \\
\text { vista artístico. São também organizados concertos matemáticos nos quais as letras das } \\
\text { músicas são formadas por ideias matemáticas de estudantes participantes das atividades em } \\
\text { sala de aula. }\end{array}$ \\
\hline $\begin{array}{c}\text { Performing New Images of Mathematicians } \\
\qquad(2012-2015) \\
\text { http://www.joyfox.ca/ }\end{array}$ & $\begin{array}{l}\text { A imagem pública da Matemática e da atividade profissional dos matemáticos é negativa e } \\
\text { estereotipada (LIM, 1999; GADANIDIS; SCUCUGLIA, 2010). Como o engajamento de } \\
\text { estudantes, pais e professores na produção de PMD pode contribuir para a mudança dessas } \\
\text { imagens negativas? Como a Matemática e os matemáticos são vistos através das lentes da } \\
\text { performance? }\end{array}$ \\
\hline
\end{tabular}

Fonte: Adaptado de: Borba, Silva \& Gadanidis (2018, p. 115-116).

Em 2016, com inspiração nas experiências com os vídeos e festivais de vídeos e Educação Matemática, Borba principiou um projeto ainda mais audacioso, a saber: "Vídeos Digitais na Licenciatura em Matemática a Distância”, batizado de E-licm@t-Tube7. Objetivou-se, com este projeto, “compreender as possibilidades da produção colaborativa de vídeos entre professores, estudantes, tutores e coordenadores, no âmbito do Ensino Superior, em cursos de Licenciatura em Matemática presenciais e $\mathrm{EaD}$ (UAB), bem como na Educação Básica" e "intensificar a produção de vídeos com conteúdo matemático

\footnotetext{
${ }^{7}$ Aprovado no Edital Produtividade em Pesquisa do CNPq (Processo no 303326/2015- 8) e no Edital Universal 2016 do CNPq (Processo: 400590/2016-6). A princípio, o projeto seria desenvolvido apenas na Educação a Distância, vinculado aos cursos de Licenciatura em Matemática da Universidade Aberta do Brasil (UAB), porém as dificuldades financeiras enfrentadas por estes cursos, bem como a dificuldade de contato fizeram com que o mesmo fosse aberto para outras Licenciaturas em Matemática e para o Ensino Básico (Domingues, 2020, p. 19).
} 
desenvolvidos, colaborativamente, por professores e alunos em diversas regiões do país" (Domingues, 2020, p. 19), por meio de festivais de vídeos digitais e Educação Matemática. Destaca-se, desse projeto o olhar atribuído ao papel das tecnologias digitais na educação, ao mostrar que existem muitos outros espaços institucionais de aprendizagem e não somente a sala de aula usual.

Ao se debruçar sobre as produções acadêmicas relativas às PMDs é possível constatar que a maioria delas estão vinculadas a esse projeto. Como exemplo, temos a tese de Domingues (2020, p. 23) que se dedicou a analisar o festival de vídeos digitais e Educação Matemática como uma complexa rede de Sistema-Seres-Humanos-Com-Mídias, com o objetivo de “compreender como o I Festival de Vídeos Digitais e Educação Matemática foi pensado, organizado e adaptado de acordo com as realidades e dificuldades vivenciadas por professores e alunos participantes no processo de produção e submissão desses vídeos". Sua pesquisa se estabeleceu, dentre outros fatores, por conta da abrangência dos festivais de vídeos citados anteriormente por meio dos projetos de pesquisa, por conta da nova roupagem que, a partir de 2006, a produção de vídeos foi tomando no GPIMEM e por conta da possibilidade de tornar visível as práticas de produção e uso de vídeos digitais desenvolvidas por professores e pesquisadores de matemática.

Com sua tese, Domingues (2020, p. 227-234) contatou, dentre outros fatores, que: a mídia vídeo, em determinadas circunstâncias, "assume um papel de sujeito dessa atividade de produzir vídeos com conteúdo de Matemática"; o vídeo, dentro do I Festival, pode ser visto como "uma aproximação ou parte do objeto de alguns sistemas na medida em que ele transformou (os alunos e a matemática "com humor") e foi transformado (linguagem utilizada no vídeo e Imagem Pública da Matemática)"; a "plasticidade/liberdade da linguagem matemática dos vídeos" presentes no I Festival. Concluiu-se, de modo geral, que o I Festival foi um evento resultado de esforços coletivos de organizadores e participantes e que o mesmo molda a sala de aula e é por ela também moldado, "na medida em que adaptações foram sendo construídas com base no diálogo entre os organizadores e participantes, ao mesmo tempo em que os vídeos foram alimentando o evento online e presencial" (Domingues, 2020, p. 240).

\section{Algumas Considerações Sobre o Caminho Percorrido}

A partir de uma das temáticas que o assunto PMD envolve - tecnologias digitais - realizamos uma breve trajetória que se inicia com a entrada da tecnologia informática nas escolas brasileiras até os mais atuais projetos que envolvem discussões das tecnologias digitais com artes e Educação Matemática, através das PMDs. Nessa trajetória, clarificamos como se deu a introdução das tecnologias digitais no ambiente escolar, com inspiração nas quatro fases das tecnologias digitais propostas por Borba, Silva e Gadanidis (2018), enfatizamos algumas críticas atribuídas a muitos dos programas e projetos apresentados e descortinamos alguns dos mais recentes projetos de pesquisa da Educação Matemática, com base nos trabalhos submetidos ao evento EBRAPEM. Nesse caminhar, podemos observar as PMDs como uma proposta potente para o ensino e aprendizagem em matemática uma vez que além de articular as tecnologias digitais à Educação Matemática, preocupa-se em incorporar as artes (performáticas) nesse processo, ao retomar a relação entre Educação Matemática e artes e ao atribuir protagonismo discente em produções oriundas dos diferentes projetos de pesquisa apresentados. Além disso, preocupa-se em romper com os muros da sala de aula, ao incorporar a sociedade nas discussões da imagem da matemática e dos professores de matemática nas discussões sobre o tema, como, por exemplo, ocorreu com o projeto Performing New Images of Mathematician.

É possível destacar também, por meio do histórico apresentado neste artigo, os recursos tecnológicos protagonistas das fases das tecnologias digitais expressos nos diferentes programas governamentais, como, por exemplo, os computadores nos laboratórios de informática, os computadores pessoais, notebooks, tablets e, mais recentemente, os projetos de pesquisa com uso dos smartphones como, por exemplo, o projeto de pesquisa que visa a construção e análise de práticas educativas em 
Educação Matemática com dispositivos touchscreen - com destaque para o pesquisador Bairral - e a produção de vídeos digitais por meio dos dispositivos móveis - com destaque para o pesquisador Borba. Cabe enfatizar que não nos restringimos a apresentação dos programas governamentais e projetos de pesquisa sobre o tema aqui tratado, mas também discutimos algumas críticas direcionadas a eles, tanto do ponto de vista da não neutralidade política e econômica presente em suas gêneses, como também os aspectos direcionados às salas de aula das escolas públicas brasileiras e seus impactos na formação discente e docente. Nesse sentido, ressaltamos também as dificuldades presentes nas produções acadêmicas analisadas com relação à inserção das tecnologias digitais em sala de aula, como, por exemplo, a falta de aparelhos atualizados e a limitação de acesso à internet; deste último ponto, destaca-se que recentemente o projeto que visava assegurar internet grátis para alunos e professores da rede pública foi vetado pelo atual governo brasileiro.

Tendo realizado esse caminhar por programas governamentais e projetos de pesquisa integrantes das três primeiras fases das tecnologias digitais em Educação Matemática, buscamos respaldo no EBRAPEM para descortinarmos as atuais propostas de pesquisa sobre o tema, bem como apresentarmos programas governamentais que integram a chama quarta fases das tecnologias digitais em Educação Matemática. Com isso, foi possível identificar, nesse recorte realizado por meio do EBRAPEM, os dois pesquisadores com maior destaque de pesquisas e citações nos anais do evento, a saber: Borba e Bairral. Possivelmente, ambos os pesquisadores se destacam nos anais do evento por conta de seus envolvimentos com a efetivação do próprio evento, sendo, inclusive, coordenadores do grupo de discussão analisado (GD 6). Dentre as atuais propostas de pesquisa em Educação Matemática que envolvem as tecnologias digitais, foi possível identificar que a produção de vídeos na perspectiva proposta pelas PMDs tem seguido um caminho que a coloca como importante fator de concatenação não só das tecnologias digitais e Educação Matemática, mas também de resgate das artes (performáticas) no ensino de matemática. Os inúmeros projetos de pesquisa citados, as parcerias internacionais e a construção de um arcabouço teórico e metodológico sobre PMDs apontam para a consolidação da temática no cenário atual da Educação Matemática e vislumbram um caminho que possibilita aos estudantes um envolvimento com as tecnologias digitais de maneira mais leve, sutil e próxima de suas realidades e vivências.

Tendo em vista, portanto, a trajetória que o tema tem seguido até aqui, fica como possibilidade de pesquisas futuras o debruçar sobre as produções acadêmicas do tema PMDs com o objetivo de identificar as potencialidades desse caminho, bem como as lacunas com relação ao tema. Com isso, evidencia-se que a discussão não se encerra aqui, pelo contrário, esperamos que dentre caminhos, a escolha do caminho aqui refletido possa contribuir para novas reflexões e produções sobre o tema.

\section{Agradecimentos: fortalecedores da caminhada}

Ao Instituto Federal de Educação, Ciência e Tecnologia (IFRJ) e ao Conselho Nacional de Desenvolvimento Científico e Tecnológico $(\mathrm{CNPq})$ pelo financiamento a pesquisa relatada neste artigo (Edital Integrado de Ensino, de Pesquisa, de Inovação e de Extensão 02/2020).

\section{Referências}

Andriola, W. B., \& Gomes, C. A. S. (2017). Programa Um Computador Por Aluno (PROUCA): uma análise bibliométrica. Educar em Revista, (63), 267-288.

Assis, A. R. (2016). Toques em Tela de Dispositivos Móveis e Processos de Construção Conceitual: contribuições para a educação geométrica. Anais do Encontro Brasileiro de Estudantes de Pós-Graduação em Educação Matemática, Paraná, Brasil, XX.

Bairral, M., Assis, A. R., \& Silva, B. C. D. (2015). Mãos em ação em dispositivos touchscreen na Educação Matemática. Seropédica: Edur.

Borba, M. C. (2003). GPIMEM-Dez anos: sua interação com o EBRAPEM. Anais Encontro Brasileiro de Estudantes de Pós-Graduação em Educação Matemática. Rio Claro: UNESP, VII.

Borba, M. C., Almeida, H. R. F. L., \& Chiari, A S. S. (2015). Tecnologias digitais e a relação entre teoria e prática: uma análise da produção em trinta anos de BOLEMA. Boletim de Educação Matemática, Rio Claro, SP, v. 29, n. 53, 1115-1140. 
Borba, M. C., Gadanidis, G., Hughes, J., \& Scucuglia, R. (2009). Digital Mathematical Performance \& Students as Performance Mathematicians: Interlocuções entre Artes e Tecnologias Informáticas em Educação Matemática. Anais do Encontro Gaúcho de Educação Matemática, Rio Grande do Sul, Brasil, X.

Borba, M., \& Lacerda, H. (2015). Políticas públicas e tecnologias digitais: um celular por aluno public policies and digital technologies: a smartphone per student. Educação Matemática Pesquisa: Revista do Programa de Estudos Pós-Graduados em Educação Matemática, $17(3)$, p. 490-507.

Borba, M. C., \& Penteado, M. G. (2017). Informática e Educação Matemática (5. Ed.). 3. Reimp. Belo Horizonte: Autêntica.

Borba, M. C., Scucuglia, R. R. S., \& Gadanidis, G. (2018). Fases das tecnologias digitais em Educação Matemática (2. ed.). 1 reimp. Belo Horizonte: Autêntica.

Brasil. (1997). Secretaria de Educação a Distância. Programa Nacional de Informática na Educação. Brasília: MEC/SEF, 23p.

Brasil. (2009). Secretaria de Educação a Distância. Um computador por aluno: formação Brasil - projeto, planejamento das ações/cursos. Brasília: MEC/SEED, 31p.

Brasil. (2012). Ministério da Educação. Site do projeto um computador por aluno - UCA.

Brito, G. S., \& Purificação, I. (2011). Educação e novas tecnologias: um(re)pensar. 3. ed. rev. atual. e ampl. Curitiba: IBPEX.

Carvalho, G. S. (2019). Vídeos digitais e Educação Matemática crítica: a álgebra da autoestima. Anais do Encontro Brasileiro de Estudantes de PósGraduação em Educação Matemática, São Paulo, Brasil, XXIII.

Castells, M. A Sociedade em Rede. (2019). Trad. Majer, R. V. (20 ed.). Revista e ampliada. São Paulo: Paz e Terra.

Domingues, N. S. (2016). Festivais de Vídeos Digitais nos Cursos de Licenciatura em Matemática da UAB. Anais do Encontro Brasileiro de Estudantes de Pós-Graduação em Educação Matemática, Paraná, Brasil, XX.

Domingues, N. S. (2020). Festival de Vídeos Digitais e Educação Matemática: uma complexa rede de Sistemas Seres-Humanos-Com-Mídias. Tese. Univ. Estadual Paulista, Rio Claro, São Paulo, Brasil.

Duarte, R. C. B. C. (2017). O uso de smartphones com GeoGebra em sala de aula: reflexões e construção de conceitos relacionados a retas paralelas cortadas por uma transversal. Anais do Encontro Brasileiro de Estudantes de Pós-Graduação em Educação Matemática, São Paulo, Brasil, XXI.

Ferreira, M. L., \& Bueno, J. L. P. (2014). O PDE e as salas do ProInfo: análise crítica sobre os projetos compensatórios na educação. Revista HISTEDBR Online, Campinas, $n^{\circ} 57, p .102-114$

Fiorentini, D., \& Lorenzato, S. (2006). Investigação em Educação Matemática: percursos teóricos e metodológicos. Campinas, SP: Autores Associados.

Fontes, B. C. (2017). O Audiovisual na Educação Matemática: um olhar para a comunicação da matemática a partir de vídeos produzidos por alunos da UAB. Anais do Encontro Brasileiro de Estudantes de Pós-Graduação em Educação Matemática, São Paulo, Brasil, XXI.

Freire, P., \& Guimarães, S. (2011). Educar coma mídia: Novos diálogos sobre educação. São Paulo: Paz e Terra.

Gil, A. C. (2002). Como elaborar projetos de pesquisa. - 4. ed. - São Paulo: Atlas.

Gimenez, H. (2019). Tendências em Educação Matemática e metodologia de pesquisa qualitativa. Anais do Encontro Brasileiro de Estudantes de PósGraduação em Educação Matemática, São Paulo, Brasil, XXIII.

Gregorutti, G. S. (2015). Performance Matemática Digital e a Imagem Pública da Matemática. Anais do Encontro Brasileiro de Estudantes de Pós-Graduação em Educação Matemática, Minas Gerais, Brasil, XIX.

Henrique, M. P. (2016). Um toque ou um arrastar direto na tela do Smartphone: reflexões e possibilidades para aprender sobre retas paralelas cortadas por uma transversal por meio do GeoGebra. Anais do Encontro Brasileiro de Estudantes de Pós-Graduação em Educação Matemática, Paraná, Brasil, XX.

Kenski, V. M. (2003). Tecnologias e ensino presencial e a distância. Campinas, SP: Papirus.

Kenski, V. M. (2008). Educação e Tecnologias: o novo ritmo da informação ( $3^{\circ}$ ed.). Campinas: Papirus.

Lacerda, H. D. G. (2015). Educação Matemática encena. 2015. 179 f. Dissertação (Mestrado em Educação Matemática) - Universidade Estadual Paulista "Júlio de Mesquita Filho", Rio Claro: São Paulo.

Lacerda, A. P. (2017). Estudo da Função Quadrática no GeoGebra em uma Turma de Jovens e Adultos. Anais do Encontro Brasileiro de Estudantes de PósGraduação em Educação Matemática, São Paulo, Brasil, XXI.

Maia, D. L., \& Barreto, M. C. (2012). Tecnologias digitais na educação: uma análise das políticas públicas brasileiras. Educação, Formação \& Tecnologias, 5 (1), 47-61.

Marques, W. (2017). Formas de numeramento em smartphones:arquitetando telas sensíveis ao toque. Anais do Encontro Brasileiro de Estudantes de PósGraduação em Educação Matemática, São Paulo, Brasil, XXI.

Moura, A. M. C. (2010). Apropriação do telemóvel como ferramenta de mediação em mobile learning: estudos de caso em contexto educativo. Tese (Doutoramento em Ciências da Educação), Instituto de Educação, Universidade do Minho, Braga, Portugal. 
Nagumo, E., \& Teles, L. F. (2016). O uso do celular por estudantes na escola: motivos e desdobramentos. Revista Brasileira de Estudos Pedagógicos, 97(246), 356-371.

Neves, L. X. (2017). Vídeos e Articulação de Representações Múltiplas: produções na educação a distância. Anais do Encontro Brasileiro de Estudantes de Pós-Graduação em Educação Matemática, São Paulo, Brasil, XXI.

Oechsler, A. R. (2016). Alunos da educação básica produzindo vídeos: aspectos metodológicos. Anais do Encontro Brasileiro de Estudantes de PósGraduação em Educação Matemática, Paraná, Brasil, XX.

Oliveira, G. W. B. (2017). Olhar, ver, reparar, representar: a potencialização da visualização com auxílio de câmeras e smartphones. Anais do Encontro Brasileiro de Estudantes de Pós-Graduação em Educação Matemática, São Paulo, Brasil, XXI.

Oliveira, L. P. F. (2016). Uso e produção de vídeos nas aulas de matemática do ensino fundamental. Anais do Encontro Brasileiro de Estudantes de PósGraduação em Educação Matemática, Paraná, Brasil, XX.

Pimentel, N. M. (2012). As políticas públicas para as Tecnologias de Informação e Comunicação e Educação a Distância no Brasil. Educ. Foco, Juiz de Fora, v. 17, n. 2 , p. $83-102$.

Romanello, L. A. (2016). Potencialidades do uso do celular na sala de aula: atividades investigativas para o ensino de função. Dissertação. Univ. Estadual Paulista, Rio Claro, São Paulo, Brasil.

Sachser, P. T. F. (2019). A procura da fórmula: teatro e matemática. 98 f. Dissertação (Mestrado em Educação Matemática) - Universidade Federal do Rio Grande do Sul, Porto Alegre: Rio Grande do Sul.

Settimy, T. F. O. (2018). Potencializando a visualização em aulas de geometria com recursos didáticos variados. Anais do Encontro Brasileiro de Estudantes de Pós-Graduação em Educação Matemática, Minas Gerais, Brasil, XXII.

Silva, E. T. (2011). Os (des)caminhos da escola: traumatismos educacionais. Barafunda metodológica, cap. 1, Cortez Editora, $24-34$.

Silva, J. A. (2016). O ensino da geometria: uma experiência com a arte do origami utilizando vídeos como recurso tecnológico. Anais do Encontro Brasileiro de Estudantes de Pós-Graduação em Educação Matemática, Paraná, Brasil, XX.

Souza, M. B. (2018). Vídeos educacionais matemáticos: um ensaio apoiado na teoria da análise fílmica. Anais do Encontro Brasileiro de Estudantes de PósGraduação em Educação Matemática, Minas Gerais, Brasil, XXII.

Souza, F. N., Barreira, j. P., Fraga, V. M., \& Braga, E. S. O. (2020). Performances Matemáticas Digitais: um diálogo entre Educação Matemática, artes e tecnologias digitais. Anais da Semana Científica-Tecnológica, Duque de Caxias, Brasil, X.

Stal, J. C. (2019). Etnomatemática: matemática presente nos vídeos. Anais do Encontro Brasileiro de Estudantes de Pós-Graduação em Educação Matemática, São Paulo, Brasil, XXIII.

Stivam, E. P. (2018). Youtubers da matemática: o papel da produção de performances matemática digitais no ensino fundamental II. Anais do Encontro Brasileiro de Estudantes de Pós-Graduação em Educação Matemática, Minas Gerais, Brasil, XXII.

Tavares, N. R. B. (2002). História da informática educacional no Brasil observada a partir de três projetos públicos. São Paulo: Escola do Futuro.

Tunin, A. S. N., Henrique, M. P., \& Bairral, M. A. (2018). Políticas de difusão das tecnologias da informação e comunicação na educação: reflexões a partir de um resgate histórico. Revista ensaios e pesquisa em educação e cultura, v. 04, Ed. EDUR.

Valente, J. A. (Org.). (1999). O computador na sociedade do conhecimento. Brasília: MEC.

Valente, J. A., \& Almeida, F. J. (1997). Visão analítica da informática na educação no Brasil: a questão da formação do professor. In: Brazilian Journal of Computers in Education, v. 1, n. 1, p. 45-60.

Vital, C. (2016). GeoGebra e Performance Matemática Digital. Anais do Encontro Brasileiro de Estudantes de Pós-Graduação em Educação Matemática, Paraná, Brasil, XX. 